\title{
People in Non-Urban Areas are Richer than those in Urban Areas? A Comment to Ghosh et al. (2010)
}

\author{
Yuta Uchiyama $^{*}, 1$ and Koichiro Mori ${ }^{1,2}$ \\ ${ }^{1}$ Research Institute for Humanity and Nature, 457-4 Motoyama, Kamigamo, Kita-ku, Kyoto, 603-8047, Japan \\ ${ }^{2}$ Shiga University, 1-1-1 Banba, Hikone 522-8522, Shiga, Japan
}

\begin{abstract}
In environmental studies, different types of system boundaries are needed. Disaggregated GIS data are crucial because they can be flexibly converted into the target boundaries. The National Oceanic and Atmospheric Administration (NOAA) data of Gross Domestic Product (GDP) should be highly evaluated as a valuable GIS data. We, however, show the problem that GDP per capita in urban areas is lower than that in non-urban areas, based on the NOAA data of GDP. This is inconsistent with the fact derived from other relevant data. We discuss possible causes of the problem: continuous linear relationship between night-time lights and GDP; leakage effects of night-time lights from urban areas to their peripheral non-urban areas; excessive infrastructures in non-urban areas as compared with their economic output; and bias in the allocation of estimated GDP data in informal sectors. We would rather contribute to the potential correction of the data than criticize the data in this paper.
\end{abstract}

Keywords: City sustainability index (CSI), disaggregated map of GDP per capita, LandScan population grid, night-time lights imagery, urban area.

\section{INTRODUCTION}

When it comes to academic research on environmental and ecological studies including social sciences, we are normally interested in system boundaries such as biospheres, ecospheres, ecosystems, human densely populated areas and so on $[1,2]$. We are rarely interested in political administrative boundaries, although environmental, social and economic data can be easily obtained in administrative boundaries. Thus, we are often confronted with problems of data availability, considering system boundaries in which we are academically interested. This is because relevant environmental, social and economic data are normally collected in terms of administrative boundaries such as countries, counties, cities, and so on [3].

In this respect, GIS data are valuable and useful, because we can flexibly arrange and adjust them to the system boundaries we target. GIS data are basically provided as raster and feature data that are smaller than administrative boundaries. For example, $1 \mathrm{~km}$ square grid data are obtainable in terms of environmental, social and economic aspects from the National Oceanic and Atmospheric Administration (NOAA) [4].

Nonetheless, we still have problems of data availability even about GIS data. As we mentioned, relevant environmental, social and economic data are normally collected, based on political administrative boundaries. Unless satellite imagery data are utilized, even GIS data are just based on the data collected in administrative boundaries. In this case, such GIS data are not useful, because they are

*Address correspondence to this author at the Research Institute for Humanity and Nature, 457-4 Motoyama, Kamigamo, Kita-ku, Kyoto, 6038047 Japan; Tel: +81-75-707-2354; E-mail: y-uchiyama@chikyu.ac.jp almost the same as the data of administrative boundaries and we cannot detect any differences in figures among areas that are smaller than administrative zones (countries, counties, cities and so on) even if we can treat small raster and feature data by relevant GIS software programs. Simply speaking, many grids show the same value within the same administrative boundaries, and it is in this case meaningless to distinguish between the grids.

In this context, Ghosh et al. [4] attempt to create an economic GIS data, more specifically $1 \mathrm{~km}$ square raster data of Gross Domestic Product (GDP). They utilize the two GIS data; the Defense Meteorological Satellite Program's Operational Linescan System (DMSP-OLS) night-time lights data developed by NOAA, and the LandScan population grid [5] produced by the Oak Ridge National Laboratory. The resolution of them is 30 arc-second, approximately $1 \mathrm{~km}$. They derive the disaggregated map of GDP by the following steps: (i) Assuming linear relationship between the intensity of the sum of night-time lights and GDP including formal and informal economies, they estimate GDP in each administrative unit; (ii) Based on the percentage contribution of the agricultural sector towards GDP on a country scale, they divide the total GDP estimated in the first step into the agricultural and non-agricultural sectors; and (iii) GDP in the agricultural sector is allocated to each 30 arc-second grid according to the LandScan population grid on a pro-rata basis, and GDP of the non-agricultural sector is distributed to the grids based on the night-time lights on a pro-rata basis. The gridded data of GDP in the two sectors are merged into the $1 \mathrm{~km}$ square raster data.

Based on our discussion above, we should highly evaluate the attempt of Ghosh et al. [4]. It is significant to create a disaggregated map of economic activity from nighttime lights data. We totally agree to the advantage of a 
disaggregated map: Economic data can be flexibly aggregated to various units such as national, state, sub-state, municipal, physical, and ecological units [4].

In fact, we have reviewed research on sustainability indices in the context of cities [3], and have been developing City Sustainability Index (CSI). The boundaries of cities do not necessarily coincide with politically administrated boundaries of cities, because the boundaries of cities (urban areas) should be defined by population density and developed area as a land use category. In this case, we would like to aggregate economic data, based on the boundaries of cities that we derive from a relevant definition. For this purpose, the database of the NOAA, resulted from Ghosh et al.'s research activities [4], seems significant.

However, we unfortunately find that the NOAA data of GDP have a serious problem. The problem is that GDP per capita in non-urban areas is higher than that in urban areas. It is inconsistent with the fact based on other relevant economic data. Thus, the purpose of this paper is to certify the problem using the NOAA data of GDP and the LandScan population grid, and to discuss possible causes towards the resolution of the problem. We strongly hope that the NOAA data will be appropriately modified and updated, because we would like to use the NOAA data in the context of CSI if possible.

\section{CLARIFICATION OF THE PROBLEM: PEOPLE IN NON-URBAN AREAS ARE RICHER THAN THOSE IN URBAN AREAS?}

In this section, we clarify the problem of the NOAA data of GDP. Using the data, we would like to show that GDP per capita in urban areas are decisively lower than that in nonurban areas. For this purpose, we show it by the following three methods: (i) we verify that GDP per capita in urban areas is lower than that in non-urban areas in each country, based on GDP per capita calculated from the NOAA GDP data and the LandScan population grid, and population density obtained from the LandScan population grid; (ii) we identify that non-urban areas with lower population density produce higher and the highest GDP per capita, based on the same data (NOAA GDP data and LandScan population grid); and (iii) we check the inconsistency of the NOAA data with other relevant data.

\subsection{Comparison of GDP Per Capita in Urban Areas with that in Non-Urban Areas}

To begin with, we provide the definition of urban areas before the discussion of the problem. We define urban areas as the land comprising grids whose population density is 2,000 people $/ \mathrm{km}^{2}$ or more on the basis of the LandScan population grid [6]. According to UNFPA [7], half of the world's population resides in "urban areas" in 2008. Urban population derived from the definition is approximately equal to half of the world's population. They should be consistent with each other.

We compare GDP per capita in urban areas with that in non-urban areas in 14 countries, using the NOAA GDP data (Table 1). The reasons why we focus on the 14 countries are that their population sizes are relatively large and that they have megacities whose population sizes are more than 10 million. The result shows that GDP per capita in urban areas is much lower than that in non-urban areas in the countries. Egypt especially shows the largest difference between them. In Egypt, GDP per capita in non-urban areas is 13.6 times as large as that in urban areas. On the other hand, the difference is the smallest in Philippines, but the difference is not so

Table 1. GDP Per Capita (from the NOAA Data) in Urban and Non-Urban Areas in 14 Countries. Sources. NOAA Data of GDP and LandScan Population Grid

\begin{tabular}{|c|c|c|c|c|}
\hline \multirow[b]{2}{*}{ Country } & \multicolumn{4}{|c|}{ GDP Per Cap.（Thousands of USD) } \\
\hline & Ave. in Country & Urban & Non-Urban & Non-Urban/Urban \\
\hline Argentina & 14.9 & 8.4 & 26.2 & 3.1 \\
\hline Bangladesh & 1.4 & 0.7 & 2.6 & 3.6 \\
\hline China & 6.1 & 3.0 & 10.2 & 3.4 \\
\hline Egypt & 5.8 & 2.4 & 32.7 & 13.6 \\
\hline India & 2.2 & 1.0 & 3.8 & 3.8 \\
\hline Indonesia & 4.0 & 2.0 & 6.5 & 3.2 \\
\hline Pakistan & 3.0 & 1.4 & 4.8 & 3.5 \\
\hline Philippines & 3.5 & 2.3 & 5.7 & 2.5 \\
\hline Russia & 16.8 & 5.3 & 31.2 & 5.8 \\
\hline USA & 54.1 & 25.7 & 69.4 & 2.7 \\
\hline
\end{tabular}


small. GDP per capita in non-urban areas is still 2.5 times as large as that in urban areas in Philippines.

\subsection{Non-Urban Areas with Lower Density Provide the Highest GDP Per Capita}

We would like to show that a large number of grids with lower population density provide GDP per capita that is higher than the average of urban grids, based on the same data sets. We focus on the following 4 countries: Indonesia, Japan, Mexico and the USA. To begin with, we convert the NOAA GDP data and the LandScan population grid to 0.1 degree (about 10km) grid data. Then, we plot each grid on the scattergraphs in each country in terms of the data of GDP per capita and the population density in each grid. This is because the countries have too many $1 \mathrm{~km}$ grids to examine by scattergraphs. Derived from the data created above, we show the relationships between population density and GDP per capita in Fig. (1), in which the range of y-axis is cut below the average GDP per capita of urban areas. The result shows that non-urban areas with lower population density produce higher GDP per capita. Moreover, non-urban areas provide the highest GDP per capita in each country.

Referring to the disaggregated maps of GDP per capita and population density in Japan, USA and Mexico (Figs. 2,
3), urban areas with high population density provide relatively low GDP per capita. In particular, there are big gaps in GDP per capita between urban and non-urban areas in Japan. It is obvious that this result should be inconsistent with the real situation in Japan.

\subsection{Inconsistency of the NOAA Data with Other Data}

In the beginning, we compare GDP per capita of 147 cities (in 59 countries) with that of their countries, based on the data from Price Waterhouse Coopers [8] and the World Bank [9]. GDP per capita of almost all the cities is higher than that of their countries except for 10 cities (Fig. 4). We should note that we may compare the cities with the other cities in each country if the urbanization rate in the country is substantially high. For example, GDP per capita of Oslo, Berlin and Naples is lower than that of their countries, and it can be caused by high urbanization rate in their countries. Considering this caveat, it turns out that GDP per capita in urban areas (cities) is mostly higher than that in non-urban areas.

Furthermore, we calculate GDP per capita in urban and non-urban areas in the 14 countries based on the World Bank (WB) data [10] for the comparison with the data from the NOAA (Table 2). In the WB data, GDP per capita in urban

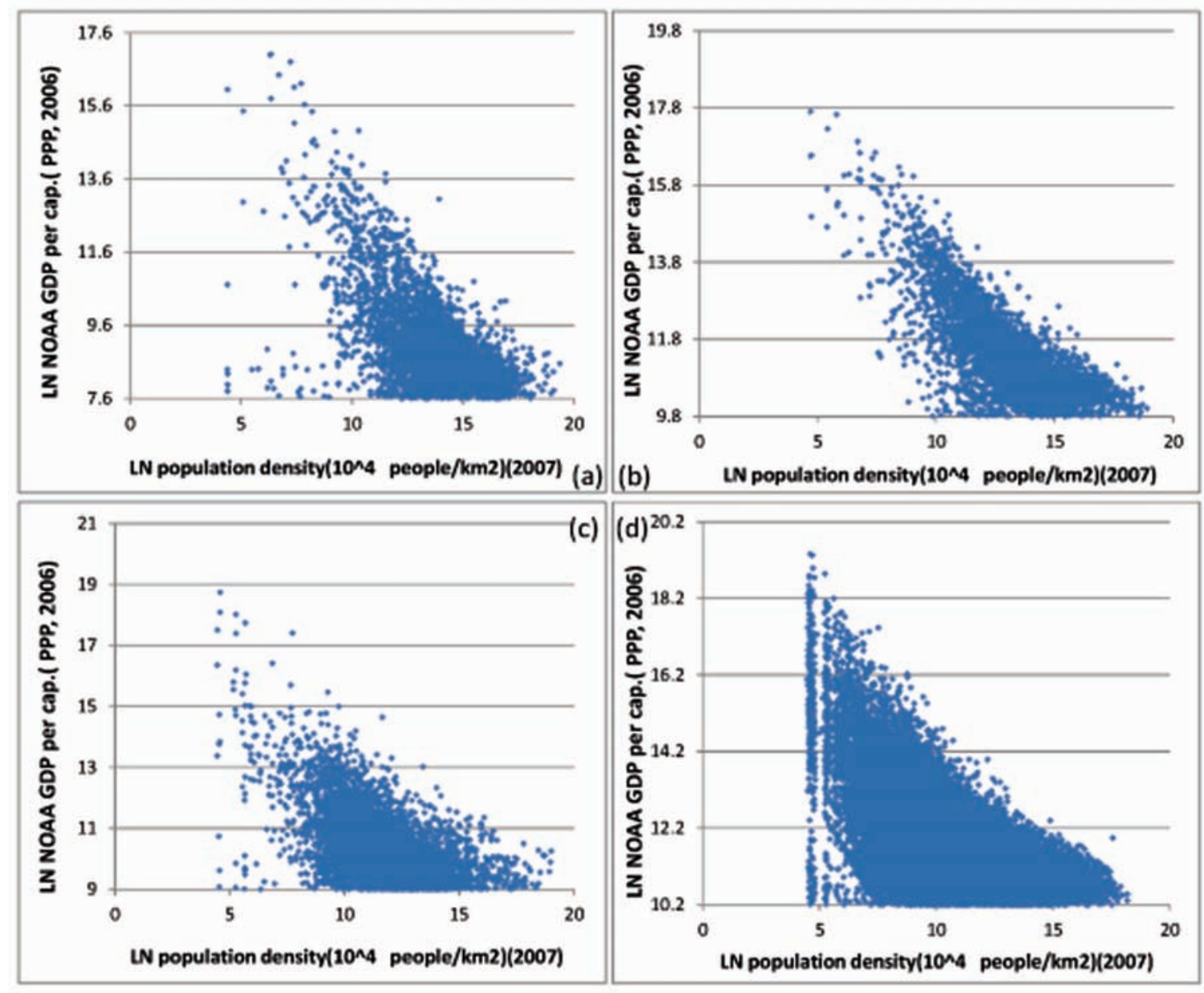

Fig. (1). Relationships between GDP per capita and population density of each grid in the 4 countries ((a) Indonesia, (b) Japan, (c) Mexico and (d) USA). NB. The y-axis is cut below the average GDP per capita in urban areas. Sources. NOAA data of GDP and LandScan population grid. 


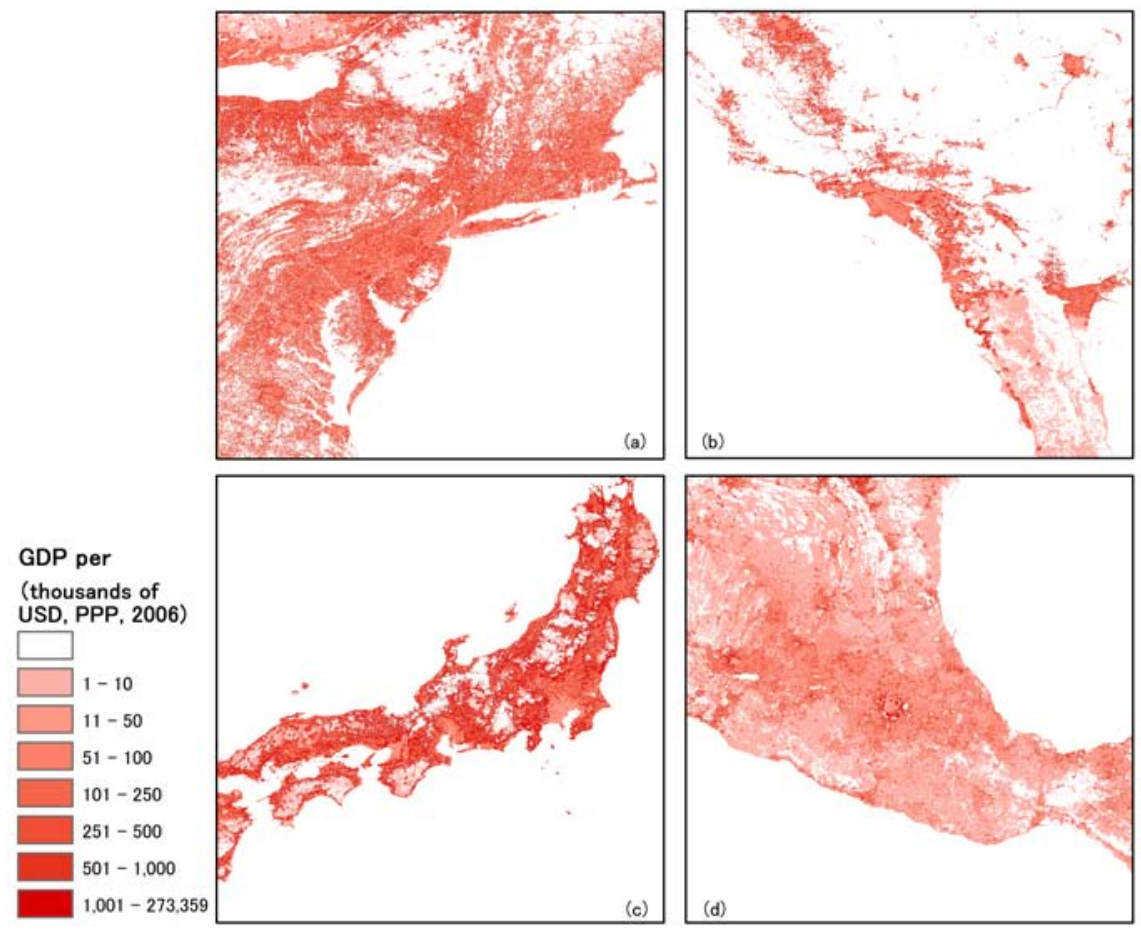

Fig. (2). Disaggregated map of GDP per capita in (a) (b) USA, (c) Japan and (d) Mexico. Sources. NOAA data of GDP and LandScan population grid.
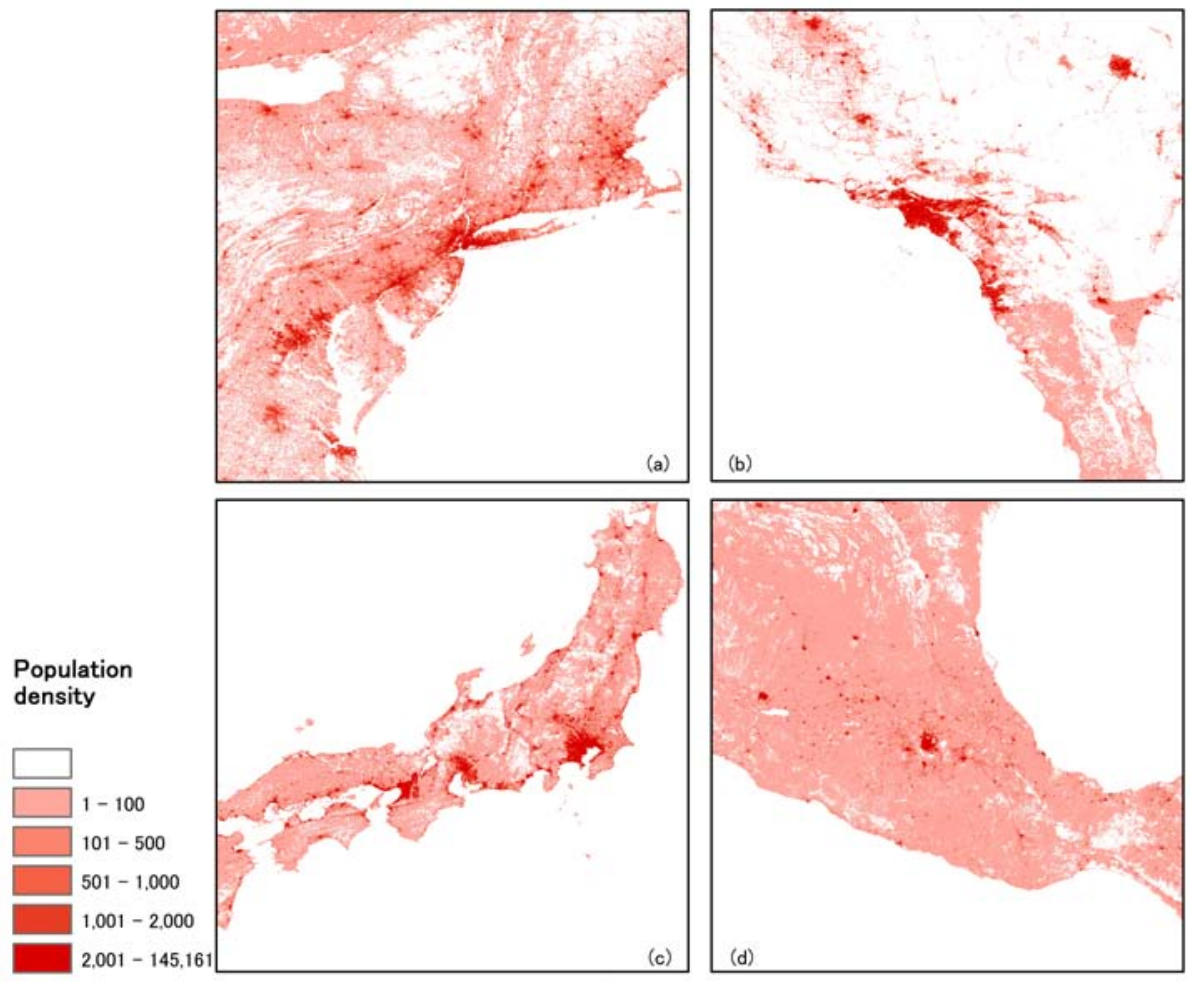

Fig. (3). Disaggregated map of population density in (a) (b) USA, (c) Japan and (d) Mexico. Source. LandScan population grid.

areas is higher than that in non-urban areas in 12 countries out of 14, except for Egypt and South Korea. Among them, the difference in Russia is the largest. In Russia, GDP per capita in urban areas is about 2 times as high as that in nonurban areas. As a result, the data of GDP per capita calculated from the NOAA is inconsistent with that obtained from the WB data in terms of the magnitude relation between urban and non-urban areas. The World Bank data shows the result that is opposite to the result derived from the NOAA data. 


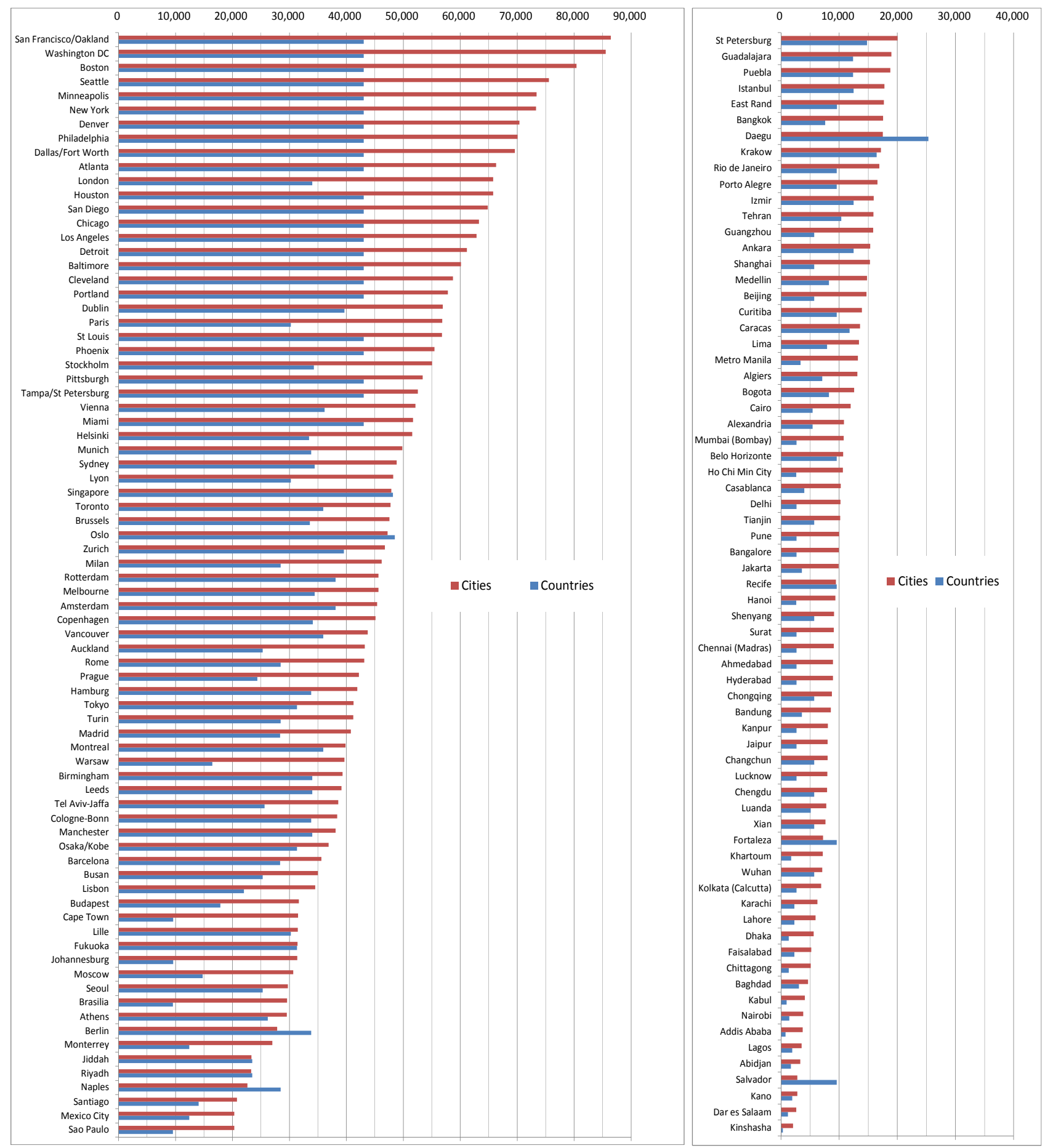

Fig. (4). Comparison of GDP per capita of 147 cities (in 59 countries) with that of their countries. Sources. Price Waterhouse Coopers [8] and the World Bank [9].

\section{DISCUSSION ON POSSIBLE CAUSES OF THE PROBLEM}

In this section, we discuss the causes of the problem that GDP per capita in urban areas is much lower than that in non-urban areas, based on the NOAA data. Based on the explanations on the methodology of deriving the $1 \mathrm{~km}$ square raster data of GDP that Ghosh et al. [4] provide, we can point out five possible causes of the problem: (i) linear relationship between the radiance of night-time lights and
GDP; (ii) continuous relationship between the intensity of night-time lights and GDP; (iii) leakage effects of night-time lights from urban areas to their peripheral non-urban areas; (iv) excessive infrastructures in non-urban areas as compared with their economic output; and (v) bias in the allocation of estimated GDP data in informal sectors.

First, linear relationship between the intensity of the sum of night-time lights and GDP is assumed, although the process of estimating the coefficient in equation (1) includes 
Table 2. GDP Per Capita (from the World Bank Data) in Urban and Non-Urban Areas in the 14 Countries. Sources: The World Bank Data and LandScan Population Grid

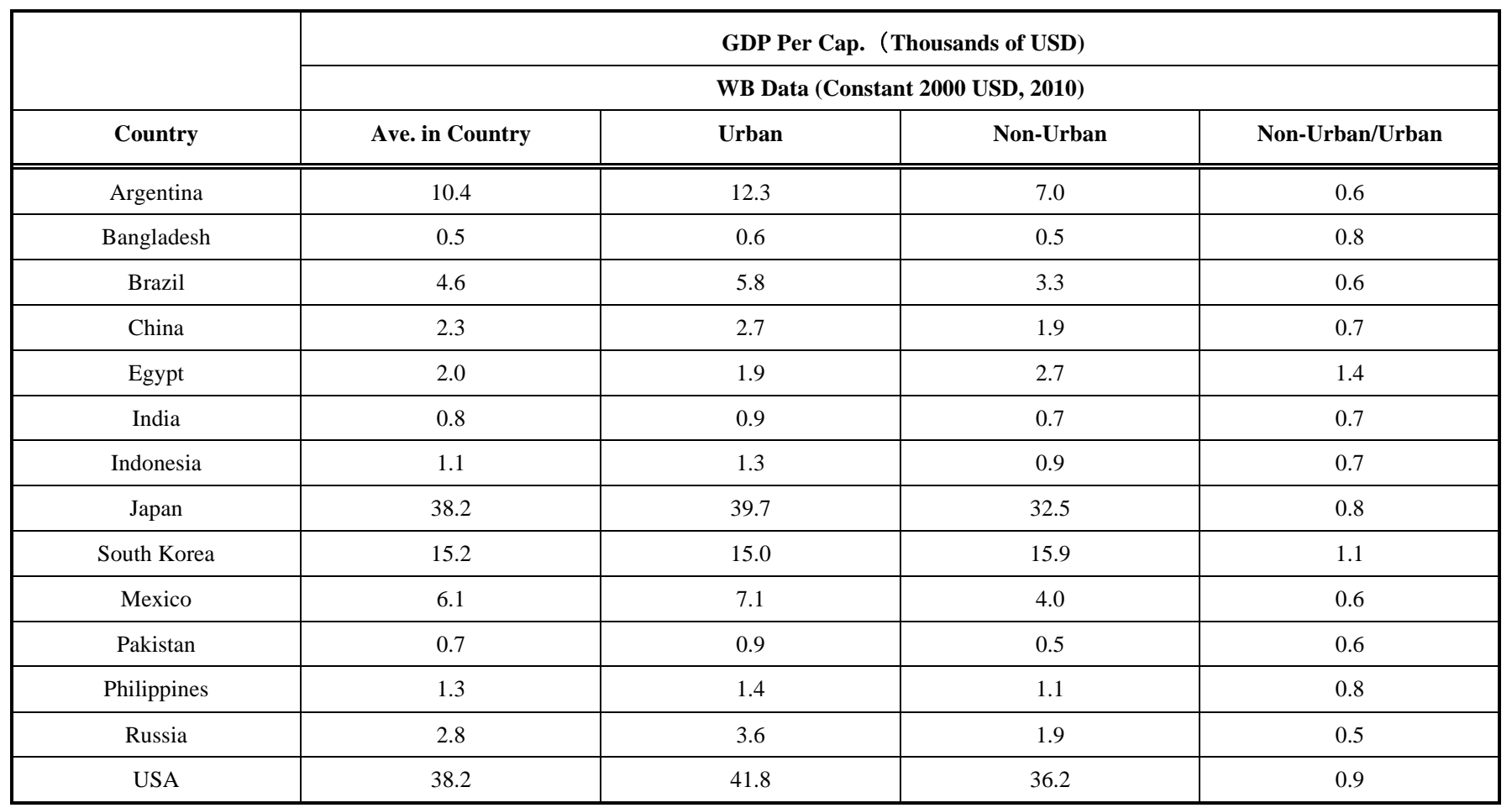

a natural logarithmic functional form (non-linear) in regression analyses in groups. The fundamental relationship between them is given by equation (1), in which $\beta_{i}^{\prime}$ is the unique coefficient for each administrative unit $i, S L_{i}$ is the sum of lights of each administrative unit $i$, and $G D P I_{i}$ is Gross Domestic Product of each administrative unit $i$.

$\beta_{i}^{\prime} * S L_{i}=G D P I_{i}$

Based on equation (1), the sum of lights is always converted into GDP at a fixed rate by the coefficient $\beta_{i}^{\prime}$ without relation to the absolute intensity of night-time lights. GDP would not necessarily increase in proportion to the sum of lights at a constant rate. Certainly GDP might proportionately increase with the increase in light intensity in the limited range of the sum of lights, but GDP might not change proportionately with the increase in the radiance of lights outside of the range. In other words, if the sum of lights exceeds a certain threshold, GDP in such areas may increase with the increase in the sum of lights at an increasing rate. In addition, the change in GDP might be more sensitive to the change in the sum of lights if the area is in advanced rich countries. We may also be able to expect that GDP will expand with the increase in the light intensity at an increasing rate if the area lies in destitute countries. Considering these, it should be better to assume non-linearity about the relationship between the sum of lights and GDP.

Second, continuous relationship between the intensity of night-time lights and GDP is assumed in the model. It is assumed that the relationship given by equation (1) always holds true over the whole range of the sum of lights and GDP. However, we can expect a truncated relationship between them. They might not be constantly correlated. Night-time lights can be treated as a kind of infrastructure. Thus, there might be many areas in which night-time lights are relatively intense as compared with the size of GDP. In other words, night-time lights are sufficiently intense even in underdeveloped areas because they are regarded as necessary infrastructure. In this case, GDP drops in a discontinuous manner.

Third, GDP of peripheral non-urban areas might be overvalued by the estimation based on the strength of nighttime lights, because the intense night-time lights possibly leak from the adjacent urban areas to the peripheral nonurban areas. For example, the circular peripheral non-urban areas close to Mexico City show higher GDP per capita, which is shown by a circular shape of zones with higher GDP per capita (Fig. 5). This type of overestimation of GDP might bring about higher and the highest GDP per capita in non-urban areas (Fig. 1).

Fourth, GDP in non-urban areas are overestimated, if physical infrastructures are sufficiently built there and if the night-time lights caused by the infrastructures are excessively intense relative to the economic output there. Observing the geographical map of GDP per capita in Japan (Fig. 2), we doubt this type of over-evaluation. In Japan, for instance, highways have been in fact excessively constructed in non-urban areas. They are not sufficiently used, and then they seem not to make contributions to producing economic output, although they emit night-time lights.

Finally, using estimated data of 'national' GDP in informal sectors [11, 12], a disaggregated map of GDP is created. The data of GDP in informal sectors are only provided in the category of countries. Thus, GDP data used in the process is just modified by the ratio of GDP in 


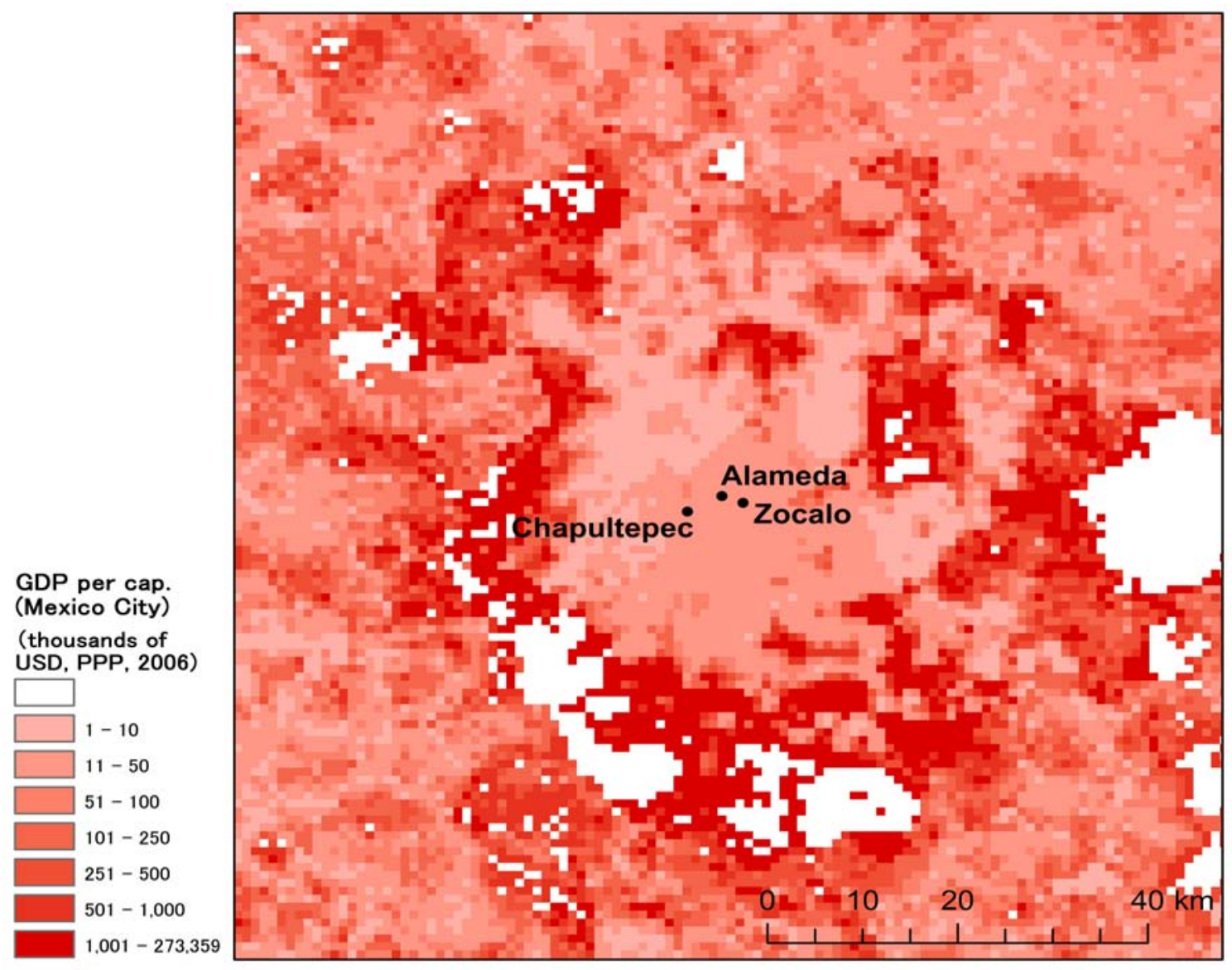

Fig. (5). Disaggregated map of GDP per capita focusing on Mexico City area. Sources. NOAA data of GDP and LandScan population grid.

informal sectors to the whole GDP. In this method, all the areas including both urban and non-urban areas have the same ratio of GDP in informal sectors. However, informal sectors have expanded in urban areas more than in non-urban areas [13]. Hence, GDP in informal sectors might be overestimated in non-urban areas, using the calculation on a pro-rata basis. On the contrary, GDP in informal sectors tends to be undervalued in urban areas by the method. This method might promote the problem that GDP per capita in non-urban areas is larger than that in urban areas.

\section{CONCLUSION}

In this paper, we clarify the problem that GDP per capita in urban areas is lower than that in non-urban areas based on the NOAA data of GDP. This is inconsistent with the fact derived from other relevant data. Specifically, we conduct the following three analyses: (i) we verify that GDP per capita in urban areas is lower than that in non-urban areas in the 14 countries, based on GDP per capita calculated from the NOAA GDP data and the LandScan population grid, and population density obtained from the LandScan population grid; (ii) we identify that non-urban areas with lower population density produce higher GDP per capita in the 4 countries such as Indonesia, Japan, Mexico and the USA, based on the same data; and (iii) we show that the results derived from the NOAA data are totally inconsistent with the data obtained from the World Bank.
Then, we discuss the possible causes of the problem. It seems to be a good idea to utilize the GIS data of night-time lights in order to estimate GDP in a disaggregated map, but it may not be so simple that we can directly convert the intensity of night-time lights into GDP data on the assumption of a continuous linear functional form. In addition, the inclusion of GDP in informal sectors seems to augment the extent of the problem.

Nonetheless, we definitely need such a disaggregated map data of GDP, high-resolution data in general, for doing academic research in terms of environmental issues. This is because we often focus on the areas that are smaller than countries and do not coincide with politically administrated areas, such as urban areas, non-urban areas, biosphere, ecosystems, watersheds and so on. Thus, we highly evaluate Ghosh et al.'s research [4] and the NOAA data. That is why we strongly hope that the disaggregated map data of GDP will be corrected and updated successfully.

\section{CONFLICT OF INTEREST}

The authors confirm that this article content has no conflict of interest.

\section{ACKNOWLEDGEMENTS}

The authors would like to thank the Research Institute of Humanity and Nature (RIHN), Professor Shin Muramatsu (the leader of the project on Megacities and the Global 
Environment) and the other project members. We appreciate anonymous referees' helpful comments.

\section{REFERENCES}

[1] Fiala N. Measuring sustainability: why the ecological footprint is bad economics and bad environmental science. Ecol Econ 2008; 67: 519-25.

[2] Graymore MLM, Sipe NG, Rickson RE. Sustaining Human Carrying Capacity: A tool for regional sustainability assessment. Ecol Econ 2010; 69: 459-68.

[3] Mori K, Christodoulou A. Review of Sustainability Indices and Indicators: Towards a New City Sustainability Index (CSI). Environ Imp Assess Rev 2012; 32(1): 94-106.

[4] Ghosh T, Powell RL, Elvidge CD, Baugh KE, Sutton PC, Anderson S. Shedding light on the global distribution of economic activity. Open Geogr J 2010; 3: 148-61.

[5] ORNL 2013. LandScan global population database. Oak Ridge National Laboratory, Oak Ridge, Tennessee. [Cited 2013 November 24]. Available from: http://web.ornl.gov/sci/landscan/

[6] Uchiyama Y, Okabe A. Categorization of 48 Mega-Regions by Spatial Patterns of Population Distribution: The Relationship between Spatial Patterns and Population Change. ISOCARP
International Planning Congress. Perm, Russia. September 10-13, 2012.

[7] United Nations Population Fund. State of World Population 2009 Facing a changing world: women, population and climate. New York: United Nations Publications 2009.

[8] Price Waterhouse Coopers. UK Economic Outlook - November 2009. London, UK 2009.

[9] The World Bank. 2008. International Comparison Program database. The World Bank, Washington, DC. [Cited 2013 November 24]. Available from: http://data.worldbank.org/indicator/NY.GDP.PCAP .PP.KD

[10] The World Bank. 2012. Global Risk Data Platform: Gross Domestic Product. United Nations Environment Programme, Geneva. [Cited 2013 November 24]. Available from: http://preview.grid.unep.ch/

[11] Schneider F. Shadow economies and corruption all over the world: What do we really Know? Open Assessm J 2007; 9: 1-66.

[12] Schneider F, Buehn A, Montenegro CE. New Estimates for the Shadow Economies all over the World. Int Econ J 2010; 24(4): 443-61.

[13] Alderslade J, Talmage J, Freeman Y. Measuring the Informal Economy - One Neighborhood at a Time, Discussion Paper Prepared for the Brookings Institution Metropolitan Policy Program, Brookings Institution, Washington, DC 2006.

(C) Uchiyama and Mori; Licensee Bentham Open.

This is an open access article licensed under the terms of the Creative Commons Attribution Non-Commercial License (http://creativecommons.org/licenses/ by-nc/3.0/) which permits unrestricted, non-commercial use, distribution and reproduction in any medium, provided the work is properly cited. 